\title{
Ovarian Mucinous Cystic Tumor Associated with Pseudomyxoma Peritonei
}

National Cancer Institute

\section{Source}

National Cancer Institute. Ovarian Mucinous Cystic Tumor Associated with

Pseudomyxoma Peritonei. NCI Thesaurus. Code C40043.

The presence of abundant mucoid or gelatinous, cellular or acellular material in the pelvis and abdominal cavity (pseudomyxoma peritonei) that is associated with the presence of an ovarian mucinous cystic tumor. In the vast majority of cases, the presence of pseudomyxoma peritonei is the result of metastasis from a primary appendiceal or gastrointestinal tumor site, and the ovarian mucinous tumor is metastatic rather than primary. 